Abstract

\title{
Integration of Biomolecular Sensing, Logic Processing of the Signals and Actuation ${ }^{+}$
}

\author{
Evgeny Katz
}

Department of Chemistry and Biomolecular Science, Clarkson University, Potsdam, NY 13699-5810, USA;

ekatz@clarkson.edu

+ Presented at the 5th International Symposium on Sensor Science (I3S 2017), Barcelona, Spain, 27-29 September 2017.

Published: 29 November 2017

A new approach to bioelectronic Sense-and-Act systems was developed with the use of modified electrodes performing sensing and substance-releasing functions. Signal-controlled release of DNA from $\mathrm{Fe}^{3+}$-cross-linked alginate hydrogel electrochemically deposited on an electrode surface was studied. The multiple input signals were logically processed with the help of the enzyme biocatalyzed reactions. Boolean logic gates, $\mathrm{OR}, \mathrm{AND}, \mathrm{INH}$, were realized with the biocatalytic reactions performed by the enzymes entrapped in the alginate film. Hydrogen peroxide produced by the enzymatic reactions resulted in the degradation of the alginate hydrogel and DNA release. The alginate degradation was facilitated by the formation of free radicals in the Fenton-type reaction catalyzed by iron cations cross-linking the alginate hydrogel. The studied approach is versatile and can be adapted to various chemical signals processed by various enzymes with differently implemented Boolean logic. This work illustrates a novel concept of functional integration of biomolecular sensing, logic processing of the signals and actuation.

(C) 2017 by the authors. Licensee MDPI, Basel, Switzerland. This article is an open access article distributed under the terms and conditions of the Creative Commons Attribution (CC BY) license (http://creativecommons.org/licenses/by/4.0/). 